\title{
Role of Fetal Sacral Length in Assessment of Gestational Age by Ultrasound
}

\author{
Amal Abdel Majid Mohamed Ahmed, ${ }^{1 *}$ MD, Mona Esayed Elkafrawy, ${ }^{2}$ MD.
}

\section{* Corresponding Author:}

Amal Abdel Majid Mohamed Ahmed Amal.mohamed53@yahoo.com

Received for publication May 16 , 2021; Accepted June 29, 2021; Published online June 29, 2021, 2021.

Copyright The Authors
published by Al-Azhar
University, Faculty of Medicine,
Cairo, Egypt. Users have the
right to read, download, copy,
distribute, print, search, or link
to the full texts of articles under
the following conditions:
Creative Commons Attribution-
Share Alike 4.0 International
Public License (CC BY-SA 4.0).
doi: 10.21608/aimj.2021.75538.1469.
1.Forensic medicine \& Clinical
toxicology Department, Faculty of
Medicine (Girls), Al-Azhar
University, Cairo, Egypt.
2. Obstetrics and Gynecology
Department Department, Faculty of
Medicine (Girls), Al-Azhar
University, Cairo, Egypt.

\section{INTRODUCTION}

Proper detection of gestational age is important for preventing premature labour inductions. Also, for the ideal timing of Chorionic Villi sampling correctly and Nuchal Translucency evaluation, amniocentesis, and elective caesarean segment section. ${ }^{1}$ In forensic cases, determining foetal age, precisely if the foetus reached full term, may be crucial. A forensic pathologist considers whether the person was born alive or stillborn, as well as whether it is viable or not. In forensic cases, determining foetal age, especially whether or not the foetus reached full term, can be crucial. ${ }^{2}$ The gestational age has been linked to ultrasonographic measurements of a variety of foetal osseous structures. The foetal skull development is detected by the biparietal diameter (BPD), head circumference, cephalic index, and inner and outer orbital nomograms. ${ }^{3}$ Fetal extremity measurements, such as femur length, have been identified to aid in the diagnosis of abnormal growth and skeletal abnormalities. ${ }^{4}$ Nomograms for other osseous system, such as the clavicle ${ }^{5}$, foot ${ }^{6}$, and mandible ${ }^{7}$, have been developed as a result of linear development. The foetal sacrum is visualized specifically during routine anatomic scanning of the foetal spine. This structure can be easily measured using ultrasonography. ${ }^{8}$

This study aimed to develop a nomogram for foetal sacral length during pregnancy and assess its utility in detecting abnormal fetal growth.

\section{PATIENTS AND METHODS}

This cross-sectional research was conducted at Alzahraa University Hospital at obstetrics and gynecology department, from January 2020 to January 2021. The study was done on singleton uncomplicated pregnancies with no anatomical abnormalities, maternal oligohydramnios or polyhydramnios, maternal diabetes, or hypertension were ruled out from the study. Patients were also removed from the study if they had abnormal menstrual cycles or if their LMP was unknown or 
could not be verified by early ultrasound. There were no congenital abnormalities in any of the deliveries, which occurred after 37 weeks .300 subjects were studied according to sample size, with gestational age from 16 to 40 weeks gestation. 240 of them average gestational age, 30 women with small gestational age. (The phrase of small for gestational age (SGA) is utilized to define a neonate whose weight is less than 10th percentile for gestational age). and 30 women with large gestational age (LGA is the term used to describe a newborn whose weight is more than 90th percentile for gestational age). The ethical committee of the department of obstetrics and gynecology, faculty of medicine, Al-Azhar University, approved this report number (202104785). Informed consent was taken after explaining the study's intent and procedure from all participants.

Histories were taken from all cases, and all patients underwent obstetric and gynecological examinations. Routine ultrasound examination using a LOGIQ v5 ultrasound scanner, were done to all women, who included, BPD, HC FL, AC, Transcerebellar diameter measurements (TCD) and sacral length (SL). The sacral length was calculated in the sagittal plane by means of the distal tip of the spine ${ }^{6}$ Sacral, and the anterior superior part of s1 using the technique used by Sherer et al. ${ }^{8 .}$ In the third trimester of gestation, the cartelgenus portion of the coccyx distal to the sacrum can be visualized but not measured with sacral length. With the occiput anterior in vertex presentation or the sacrum anterior in breech presentation, the sacrum is clearly visible then freezes and measure (Figure 1). After that, all of the parameters were registered. All data was statistically analyzed to see whether foetal sacral length played a role in determining gestational age. The following tables and figures show the findings of the current study.

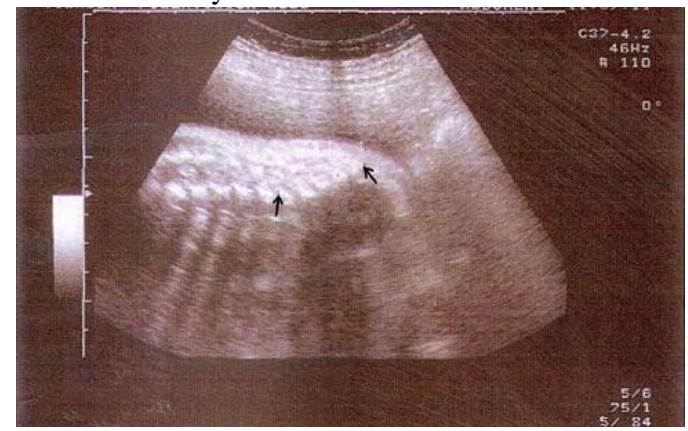

Fig 1: Fetal sacral length by ultrasound measurement (sherer etal 1993).

\section{Sample size}

Sample size according to a previous report ${ }^{9}$, the MedCalc ${ }^{\circledR}$ version 12.3.0.0 software "Ostend, Belgium" was applied to calculate sample size, calculator of Statistics based on 95 percent interval of trust, and study power of 80 percent with error of 5\%. ${ }^{9}$ The sample size was estimated based on these values, and a sample size of 117 women was found to be sufficient to find such a correlation. The number of pregnant women in the study was increased to 300 cases.

\section{Analysis of the data:}

The statistical package for social sciences, version 20.0, was used to analyze the results (SPSS Inc., Chicago, Illinois, USA). The mean and standard deviation were used to express quantitative results (SD). The frequency and percentage of qualitative data were used to represent the data.

\section{RESULTS}

This a cross-sectional analysis was conducted at Alzahraa University Hospital, 300 pregnant women were studied for a year, from January 2020 to January 2021. The first day of the last menstrual period (LMP) or an early ultrasound within the first three months of pregnancy were used to calculate gestational age in this analysis. Fetal sacral lengths (SL) were determined using two-dimensional sonography at different stages of pregnancy at various ranging from 16 to 40 weeks according to the LMP. The age of the studied group's ranged from 20 to 40 years old. According to demographic data statistics, there was no statistically significant difference between groups. Except in birth weight between the examined cases, with $\mathrm{P}$ value 0.001 (Table 1). The current study indicates a rise in foetal sacral length with increasing gestational age (Table2) (Figure 2). The mean of sacral length by $\mathrm{mm}$ was $18.17 \mathrm{~mm}$ at $16-24 \mathrm{wks}$ of gestational age, $27.85 \mathrm{~mm}$ at $25-33 \mathrm{wks}$, and $36.70 \mathrm{~mm}$ at $34-40 \mathrm{wks}$, the gestational age nearly equal to sacral length by $\mathrm{mm}$ (Table 3) (Figure 3).

The measure of BPD, HC, FL, AC,TCD, and sacrum length measure were calculated to be $75.24 \pm 7.18$ $\mathrm{mm}$ (range 49.48-90.34 mm), 265.66 $21.95 \mathrm{~mm}$ (range 169.68- 324.01 mm), $55.39 \pm 5.75 \mathrm{~mm}$ (range

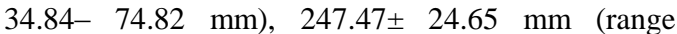
145.26- $321.42 \mathrm{~mm}$ ), $28.80 \pm 2.65$ (Table 4). Shows the linear increase as the connection between gestational age and sacral length, the level of increase in sacral length was calculated using the formula [gestational age $=3.601+1.087 \mathrm{x}$ sacrum length $(\mathrm{r}=0.991, \mathrm{R} 2=0.983)$. There was a statistically significant association between BPD, HC, FL, AC, TCD, and sacral length and the other sonographic measures, with the SL having the least error in the average gestational age (1.050) (Table 5). The least error was also observed in the (34-40 wks.) gestational age (Table 6).

In the current study, 60 foetuses with abnormal growth (30 cases with LGA and 30 cases with SGA) determined after birth. There is a major difference in BPD, head circumference, and femur length with gestational age for the LGA foetuses in our sample, while TCD and sacral length, there was no substantial distinction between the expected and actual gestational age. There are also major variations in the nomograms of BPD, head circumference, and femur length for SGA foetuses, but no differences in TCD and sacral length as the real gestational age (Table 7). 


\begin{tabular}{|l|l|l|l|l|}
\hline Demographic data & $\begin{array}{l}\text { Average gestational } \\
\text { age group }(\mathrm{n}=240)\end{array}$ & $\begin{array}{l}\text { Small gestational } \\
\text { age group }(\mathrm{n}=30)\end{array}$ & $\begin{array}{l}\text { Large gestational } \\
\text { age group }(\mathrm{n}=30)\end{array}$ & p-value \\
\hline Age (years) & $33.2 \pm 3.8$ & $33.2 \pm 3.8$ & $34.2 \pm 3.2$ & 0.221 \\
\hline Maternal weight $(\mathrm{kg})$ & $55.2 \pm 7.8$ & $53.2 \pm 8.0$ & $56.2 \pm 8.0$ & 0.144 \\
\hline Maternal height $(\mathrm{cm})$ & $162.0 \pm 4.4$ & $161.0 \pm 4.8$ & $160.7 \pm 5.8$ & 0.134 \\
\hline BMI $\left(\mathrm{kg} / \mathrm{m}^{2}\right)$ & $21.0 \pm 2.8$ & $20.2 \pm 2.8$ & $21.2 \pm 2.8$ & 0.140 \\
\hline Parity & & & & \multirow{2}{*}{0.536} \\
\hline PG & $164(63.1 \%)$ & $22(71.9 \%)$ & $19(61.9 \%)$ & \multirow{2}{*}{} \\
\hline G2+ Multigravida & $96(36.9 \%)$ & $8(28.1 \%)$ & $11(38.1 \%)$ & $<0.001$ \\
\hline Birth weight $(\mathrm{kg})$ & $3309.9 \pm 17.7$ & $2660.1 \pm 23.2$ & $3660.1 \pm 23.2$ & \\
\hline
\end{tabular}

Table 1: Comparison between the studied groups as regard to demographic data. (Using: One Way Analysis of variance; $x^{2}$ : Chi-square test; $p$-value $>0.05 N S$ ).

\begin{tabular}{|l|c|c|c|}
\hline \multirow{2}{*}{ Gestational Age (wks) } & \multicolumn{3}{|c|}{ Sacral Length (mm) } \\
\cline { 2 - 4 } & \pm 2 SD & Mean & \pm 2 SD \\
\hline 16 & 14.0 & 14.4 & 14.8 \\
\hline 17 & 15.0 & 15.3 & 15.6 \\
\hline 18 & 16.0 & 16.2 & 16.5 \\
\hline 19 & 17.5 & 17.8 & 18.0 \\
\hline 20 & 17.8 & 18.1 & 18.4 \\
\hline 21 & 18.6 & 19.1 & 19.7 \\
\hline 22 & 19.4 & 19.9 & 20.4 \\
\hline 23 & 20.1 & 20.9 & 21.6 \\
\hline 24 & 20.9 & 21.8 & 22.4 \\
\hline 25 & 21.7 & 22.8 & 23.6 \\
\hline 26 & 22.5 & 23.8 & 24.9 \\
\hline 27 & 23.8 & 25.3 & 26.4 \\
\hline 28 & 25.2 & 26.7 & 27.6 \\
\hline 29 & 25.6 & 27.3 & 28.2 \\
\hline 30 & 29.4 & 29.6 & 29.8 \\
\hline 31 & 30.5 & 30.8 & 31.0 \\
\hline 32 & 31.6 & 31.6 & 31.8 \\
\hline 33 & 32.3 & 32.7 & 32.9 \\
\hline 34 & 33.2 & 33.7 & 34.0 \\
\hline 35 & 34.1 & 34.7 & 35.0 \\
\hline 36 & 35.5 & 35.8 & 36.0 \\
\hline 37 & 36.5 & 36.8 & 37.0 \\
\hline 38 & 37.6 & 37.8 & 38.0 \\
\hline 39 & 38.5 & 38.8 & 39.0 \\
\hline 40 & 39.0 & 39.2 & 39.5 \\
\hline
\end{tabular}

Table 2: Association between fetal sacral length " $\mathrm{mm}$ " by gestational age "wks".

\begin{tabular}{|l|c|c|c|}
\hline \multirow{2}{*}{ Gestational Age (wks) } & \multicolumn{3}{|c|}{ Sacral Length (mm) } \\
\cline { 2 - 4 } & \pm 2 SD & Mean & \pm 2 SD \\
\hline GA 16-24 wks. & 17.60 & 18.17 & 18.71 \\
\hline GA 25-33 wks. & 27.05 & 27.85 & 28.61 \\
\hline GA 34-40 wks. & 36.14 & 36.70 & 37.26 \\
\hline
\end{tabular}

Table 3: Association between fetal sacral length "mm" and gestational age "wks".

\begin{tabular}{|l|c|c|c|c|c|c|c|c|}
\hline \multirow{2}{*}{ Ultrasound } & \multicolumn{2}{|c|}{$\begin{array}{c}\text { GA 16-24 wks. } \\
(\mathrm{n}=108)\end{array}$} & \multicolumn{2}{c|}{$\begin{array}{c}\text { GA 25-33 wks. } \\
(\mathrm{n}=108)\end{array}$} & \multicolumn{2}{c|}{$\begin{array}{c}\text { GA 34-40 wks. } \\
(\mathrm{n}=84)\end{array}$} & \multicolumn{2}{c|}{ ANOVA } \\
\cline { 2 - 10 } & Mean & \pm SD & Mean & \pm SD & Mean & \pm SD & F & p-value \\
\hline BPD & 49.48 & 8.44 & 75.24 & 7.18 & 90.34 & 2.52 & 902.803 & $<0.001^{* *}$ \\
\hline HC & 169.68 & 30.51 & 265.66 & 21.95 & 324.01 & 12.35 & 1071.089 & $<0.001^{* *}$ \\
\hline FL & 34.84 & 7.10 & 55.39 & 5.75 & 74.82 & 7.43 & 837.085 & $<0.001 * *$ \\
\hline AC & 145.26 & 32.72 & 247.47 & 24.65 & 321.42 & 16.31 & 1111.803 & $<0.001^{* *}$ \\
\hline TCL & 19.84 & 2.59 & 28.80 & 2.65 & 36.87 & 2.04 & 1134.261 & $<0.001^{* *}$ \\
\hline SL & 18.17 & 2.49 & 27.85 & 3.60 & 36.70 & 1.98 & 1028.563 & $<0.001^{* *}$ \\
\hline
\end{tabular}

Table 4: Comparison between GA wks." according to their ultrasound regarding BPD, HC, FL, AC, TCL and SL in the study groups. 

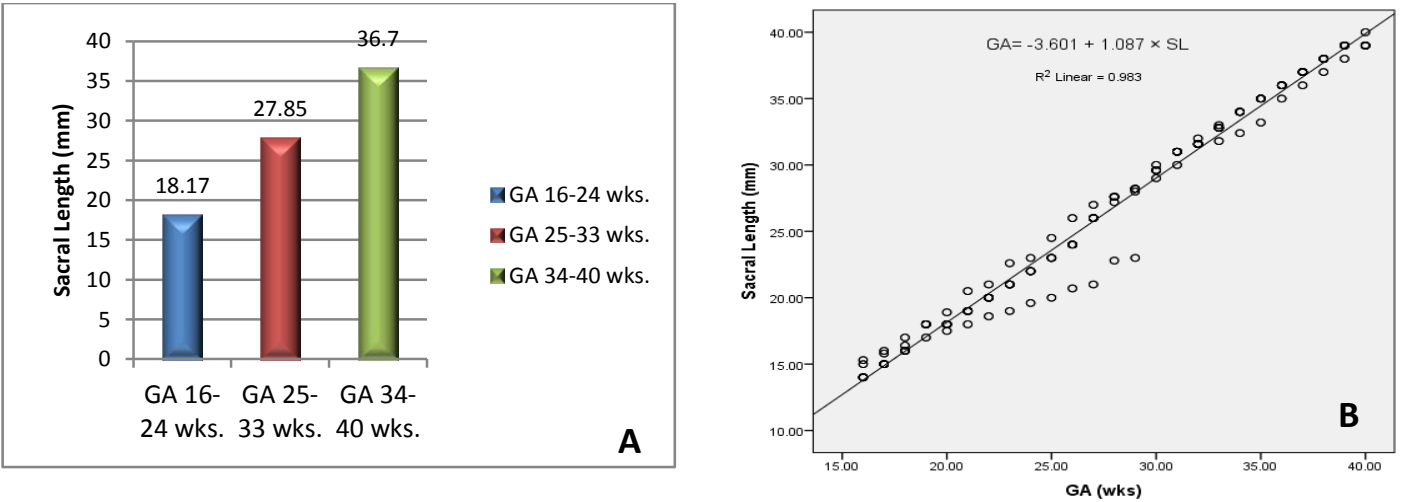

A Fig 3: (A) Association between fetal sacral length by "mm" to gestational age by "wks. B Fig 2: Scatter plot between fetal sacral length "mm" by gestational age "wks".

\begin{tabular}{|l|c|c|c|c|c|}
\hline \multicolumn{1}{|c|}{ Ultrasound } & $\mathrm{R}$ & $\mathrm{r} 2$ & $\begin{array}{c}\text { Standard error } \\
\text { of estimate }\end{array}$ & $\begin{array}{c}\text { Present } \\
\text { study t-test }\end{array}$ & p-value \\
\hline $\mathrm{GA}=1.662+2.448 \times \mathrm{BPD}$ & 0.982 & 0.965 & 3.370 & 90.668 & $<0.001^{* *}$ \\
\hline $\mathrm{GA}=-9.221+9.167 \times \mathrm{HC}$ & 0.987 & 0.974 & 10.720 & 106.704 & $<0.001^{* *}$ \\
\hline $\mathrm{GA}=-13.156+2.378 \times \mathrm{FL}$ & 0.992 & 0.984 & 2.190 & 135.434 & $<0.001^{* *}$ \\
\hline $\mathrm{GA}=-59.679+10.395 \times \mathrm{AC}$ & 0.892 & 0.813 & 9.330 & 64.148 & $0.004^{*}$ \\
\hline $\mathrm{GA}=-0.202+1.001 \times \mathrm{TCL}$ & 0.998 & 0.997 & 0.400 & 310.414 & $<0.001^{* *}$ \\
\hline $\mathrm{GA}=-3.601+1.087 \times \mathrm{SL}$ & 0.991 & 0.983 & 1.050 & 129.733 & $<0.001^{* *}$ \\
\hline
\end{tabular}

Table 5: Regression equations measurements for detection of gestational age based on ultrasonographic measurement.

\begin{tabular}{|l|c|c|c|c|c|}
\hline & $\mathrm{R}$ & $\mathrm{r} 2$ & $\begin{array}{c}\text { Standard error } \\
\text { of estimate }\end{array}$ & $\begin{array}{c}\text { Present study } \\
\text { t-test }\end{array}$ & $\mathrm{p}$-value \\
\hline GA 16-24 wks $=-0.191+0.918 \times \mathrm{SL}$ & 0.958 & 0.918 & 0.715 & 34.453 & $<0.001^{* *}$ \\
\hline GA 25-33 wks= -9.414+1.285 $\times \mathrm{SL}$ & 0.927 & 0.859 & 1.354 & 25.452 & $<0.001^{* *}$ \\
\hline GA 34-40 wks= $1.599+0.949 \times \mathrm{SL}$ & 0.966 & 0.934 & 0.511 & 34.047 & $<0.001 * *$ \\
\hline
\end{tabular}

Table 6: Regression equations measurements for detection of level of gestational age depend on SL "mm".

\begin{tabular}{|l|c|c|c|}
\hline Ultrasound & Mean Difference (wks) & Present study t-test & Significant \\
\hline Small of GA & & & \\
\hline BPD & -1.48 & 6.86 & $<0.001$ \\
\hline HC & -1.33 & 6.16 & $<0.001$ \\
\hline FL & -2.92 & 8.94 & $<0.001$ \\
\hline AC & -2.00 & 7.61 & $<0.001$ \\
\hline TCL & 0.46 & 1.92 & $>0.05$ \\
\hline SL & 0.40 & 1.30 & $>0.05$ \\
\hline Large of GA & & & \\
\hline BPD & 1.62 & 7.18 & $<0.001$ \\
\hline HC & 2.77 & 8.59 & $<0.001$ \\
\hline FL & 1.41 & 6.28 & $<0.001$ \\
\hline AC & 1.94 & 7.59 & $<0.001$ \\
\hline TCL & 0.48 & 1.97 & $>0.05$ \\
\hline SL & 0.24 & 1.01 & $>0.05$ \\
\hline
\end{tabular}

Table 7: Mean differences of estimated gestational age from actual gestational age in fetuses with abnormal growth.

\section{DISCUSSION}

Clinical decisions during pregnancy are based on gestational age, accurate pregnancy dating is critical in obstetric management. The practice of determining gestational age early in pregnancy is beneficial in detecting growth abnormalities later in pregnancy. The precise measurement of gestational age and knowledge of foetal development have been shown to be critical which are common in normal and highrisk pregnancies are managed in this way. Estimating gestational age is relevant in forensic medicine for a variety of reasons, including vitality assessments, medical termination of pregnancy, diagnosis of pathological conditions that could impair development, and distinguishing between aborted 
and stillborn foetuses, as well as legal and illegal abortions. The only biological profile attribute accurately obtainable from foetal remains is gestational age, which is useful in forensic settings to help identification or assess foetal viability. ${ }^{10}$

Furthermore, one of the most relevant goals of ultrasonography in pregnancy is to determine gestational age. The biometric evaluation of BPD, $\mathrm{HC}, \mathrm{AC}, \mathrm{FL}$, and TCD are the majority used widely for foetal growth and gestational age assessment. The sonographic examination of BPD and FL has been emphasized as the most accurate tool for determining gestational age. BPD estimation, on the other hand, can be difficult. If the foetal head is deeply engaged in direct occipitoanterior or occipito-posterior positions, or if the foetus has a distinct or irregular cranial form. ${ }^{11,12}$

Likewise, FL calculation is an easy and precise tool for estimating foetal gestational age as well as detecting foetal limb abnormalities and growth disturbances. Due to unsatisfactory foetal position or vigorous foetal movement, it may be difficult to achieve an accurate measurement of FL. ${ }^{11,13}$ Another factor to consider is the cumulative effect of factors on foetal growth, which changes over time as the pregnancy progress. As a result, standard biometrical parameter variability increases, till reach a maximum of 7 weeks at term. ${ }^{13,14}$ After 36 weeks of near-term pregnancy the average difference between the TCD's detection of gestational age increased to 6 days. ${ }^{15} \mathrm{As}$ a result, using BPD, HC, AC, FL and TCD to predict gestational age becomes less accurate during the third trimester. ${ }^{13,15,14}$ The study group's average age ranged from 20 to 40 years old. According to demographic statistics, there is no statistically significant difference between groups. However, there are statistically significant differences between the studied cases in terms of birth weight with $\mathrm{P}$ value of 0.001 (Table 1).

This nearly agrees with Diyva et al. ${ }^{1}$ and Ozat et al. 9 , who reported the mean age of the studied population to be (19-36 y) and (18-40 y) respectively in their studies. The current study found association increasing foetal sacral length with increasing the gestational age in a (Table 2) (Fig 2). As the mean SL was $18.17 \mathrm{~mm}$ at $16-24$ gestational age by weeks, $27.85 \mathrm{~mm}$ at $25-33$ weeks, and $36.70 \mathrm{~mm}$ at $34-40$ weeks, (Table 3) (Fig 3). This is agreed with the results of Ozat et al. (2011) ${ }^{9}$, who examined 2,184 pregnant women who were referred to routine prenatal care and found that foetal sacral length increases with increasing gestational age. The linear regression equations show a statistically significant association between gestational age and ultrasound measurements of BPD, HC, AC, FL, and sacrum length. Diyva et al. ${ }^{1}$ agree with this report, stating that sacral length can be applied as a valid routine parameter in 100 pregnant women with gestational age (15-40 wks.) and can used in situations where other standard methods were difficult to measure or detect incorrectly measurement of gestational age. Sherer et al. ${ }^{8}$ were the pioneer to identify the usual sacral length restrictions and show that sacral length, gestational age, and other typical foetal growth measures have a strong association. The sacrum length of 506 normal single pregnancy and 80 single pregnancy with abnormal growth were contrasted by these researchers, as a result, the average sacrum length in millimeters was found to be nearly similar to the pregnancy age in weeks. According to the current analysis, sacral length increases linearly as gestational age increases. In the current study, for foetuses with a gestational age of weeks, the rate of increase in sacral length was calculated as [gestational age $=3.601+1.087 \mathrm{x}$ sacrum length with $(\mathrm{r}=0.991, \mathrm{R} 2=0.983)]$ for foetuses with a gestational age by weeks (figure 2). BPD, HC, FL, AC, TCD, and sacral length had statistically significant correlations with the other sonographic measures, with different standard errors, and the least error was observed in TCD and SL correlations of 0.400 and 1.050 days respectively (Table 5). The least error was also observed in the (34-40wks) gestational age (Table 6). This agrees with Pajak et al. ${ }^{16}$ who looked at 453 cases and found a clear connection between sacrum length and gestational age, as well as sacrum length and BPD or FL calculation. As a result, foetal sacral length was studied as a measurement of gestational age on its own study. A linear regression equation exists suggesting the connection between gestational age and sacrum length, according to Ozat et al. ${ }^{9}$, [gestational age $=-0.05 \pm 1.019$ sacrum length $(r=0.96, R 2=0.98)]$, the formula for the rate of increase in sacrum length of foetuses with a gestational age of more than 28 weeks whereas [gestational age $=-0.09 \pm 1.329$ sacrum length $(r=$ $0.94, \mathrm{R} 2=0.96)]$ had the same formula for foetuses who were less than 28 weeks along in their pregnancy. The current findings were agreement with those of Sherer et al., and Pajak et al. ${ }^{8,16}$. As a result, foetal sacral length increased in a linear fashion as gestational age increased. Karabulut et al. ${ }^{17}$ on the other hand, who asserted the sacrum length does not change during pregnancy and that the connection between gestational age and sacral length is weaker in the third trimester Similar evidence collected from the anatomical dissect of aborted fetuses structure backed up their results. This is due to the ultrasound's variable resolution. Another point of contention is the age at which sacral ossification centers can be visualized sonographically. Sherer et al. ${ }^{8,15}$ showed that sacral ossification centers were present by the 16th week of pregnancy, while another analysis found sacral ossification centers existed before the age of 15 weeks, Karabulut et al. ${ }^{17}$ on the other hand, observed sacral ossification centers as early as the 14th gestational week. Sacral ossification centers could be identified by 16 weeks of gestation. In the current research, 60 foetuses with abnormal growth (30 with LGA and 30 with SGA) had substantial variations in $\mathrm{BPD}, \mathrm{HC}$, and femur length, with the LGA foetuses having an overestimated gestational age. In the case of TCD and sacral length, however, there was no statistically significant distinction between the expected and real gestational age. There were also major variations in the nomograms of BPD, head circumference, and femur length for SGA foetuses, but no differences in TCD and sacral length as the real gestational age (Table 7). This was consistent with the findings of Sherer et al. ${ }^{8}$ who 
looked at 80 foetuses with abnormal growth and found a significant difference in BPD, head circumference, and femur length for LGA foetuses. However, sacral length was showing no difference between the expected and current gestational age. Predictions of gestational age based on BPD nomograms, head circumference, femur length, and sacral length for SGA foetuses all are underestimated the real gestational age. As compared to gestational age differences derived from BPD, head circumference, and femur length measurements, sacral length measurements had the smallest magnitude of gestational age disparity ${ }^{18}$. The foregoing inconsistencies can be due to differences in the ultrasound machine's resolution capacity and differentiability in the sonographers' individual experience ${ }^{12}$. The foetal sacral length tends to be a simple and useful parameter. This has a clear and direct relationship with gestational age and other biometrical evaluation. As a result, foetal sacral length may be used as a useful addition method in both foetal growth assessment and gestational age prediction. To evaluate the importance of foetal sacral length in prenatal period follow-up, further research is required.

\section{CONCLUSION}

Final thoughts, the foetal sacral length tends to be a simple and useful parameter that can be used as a dependable routine parameter and supplement tool in estimation of foetal growth and the prediction of gestational age in both normal and abnormal foetal growth, as well as an alternative in situation where it's difficult to determine other routine parameters to predict incorrectly. An over-estimation of fetal age would influence the identification of an individual and could also affect the consequence of a forensic case. This research would benefit not only obstetricians but also medicolegal specialists in assessing gestational age, assisting in the administration of justice. Further researches are requested to evaluate the importance of fetal sacral length in prenatal follow-up.

\section{REFERENCES}

1. Diyva JT, Sreelakshmi U and Sonal K. Ultrasonographic evaluation of fetal sacral length measurement as anew parameter for assessment of gestational age. International Medical Journal. 2015; 2(S): 277-84.

2. Kumar S and Ketki K. Parameters for gestational age estimation. International Journal of Current Research. June 2017; 9 (06):52096-9.

3. Engle W. American Academy of pediatric Committee on Fetus and Newborn. Age terminology during the perinatal period. Pediatrics. 2004; 114(5):1362-54.

4. Jeanty P, Rodesch F and Delbeke D. Estimation of gestational age from measurements of fetal long bones. J Ultrasound Med.1984; 3:75-9.

5. Yarkoni S, Schmidt W and Jeanty P. Clavicular measurement:a new biometric parameter for fetal evaluation. J Ultrasound Med. 1985; 4:467-70.
6. Mercer BM, Sklar S, Shariatamadar A, et al. Fetal foot length as a predictor of gestational age. AM J OBSTET GY iecol. 1987; 156:350-5.

7. Otto $\mathrm{C}$ and Platt LD. The fetal mandible measurement; an objective determination of fetal jaw size. Ultrasound Obstet Gynecol. 1991; 1: 12-7.

8. Sherer DM, Abramowicz JS, Plessinger MA, et al. Foetal sacral length in the ultrasonographic assessment of gestational age. AM J Obstet Gynecol. 1993; 168: 626-33.

9. Ozat M, Kanat-Pektas M, Gungor T, et al. The significance of fetal sacral length in the ultrasonographic assessment of gestational age. Archives of Gynecology and Obstetrics. 2011; 283(5):999-1004.

10. Cristiana Carneiro1, Francisco Curate, Inmaculada Alemán, et al. Fetal age at death estimation on dry bone: testing the applicability of equations developed on a radiographic sample. Revista Argentina de Antropología Biológica. 2019; 21(2):1-10.

11. Varol F, Saltik A, Kaplan PB, et al. Evaluation of gestational age based on ultrasound fetal growth measurements. Yonsei Med J. 2001; 42(3):299303.

12. Salomon LJ, Bernard JP, Duyme M, et al. Revisiting first-trimester fetal biometry. Ultrasound Obstet gynecol. 2003; 22(1):63-4.

13. Dudley NJ and Chapman E.The importance of quality management in fetal measurement. Ultrasound Obstet Gynecol. 2002; 19 (2):190-6.

14. Bavini S, Mittal $\mathrm{R}$ and Mendiratta SL. Ultrasonographic measurement of the transcerebellar diameter for gestational age estimation in the third trimester. Journal of Ultrasound. 2021; 9:1-7.

15. Caughey AB, Nicholson JM and Washington AE. First versus second trimester ultrasound: the effect on pregnancy dating and perinatal outcomes. Am J Obstet Gynecol. 2008; 198(6):703.

16. Pajak J, Heimrath J, Gabrys M, et al. Usefulness of ultrasonographic measurement for fetal sacral length in assessment of gestational age in physiologic pregnancy. Ginekol Po. 1998; 69(7):563-9.

17. Karabulut KA, Koyluoglu B and Uysal I. Human foetal sacral length measurement for the assessment of foetal growth and development by ultrasonograpy and dissection. Anat Histol Embryol. 2001;10: 141-6.

18. Abramowicz JS, Jaffe $\mathrm{R}$ and Warsof SL. Ultrasonographic measurement of fetal femur length in growth disturbances. AMJ Obsth Gynt Coi. $1989 ; 161 ; 1137-40$. 